\title{
SENSITIVITY TEST OF PARAMETERIZATION SCHEMES OF MM5 MODEL FOR PREDICTION OF THE HIGH IMPACT RAINFALL EVENTS OVER BANGLADESH
}

\author{
M. N. Ahasan ${ }^{1, *}$, M. A. M. Chowdhury ${ }^{2}$, D. A. Quadir ${ }^{3}$ \\ ${ }^{1}$ SAARC Meteorological Research Centre (SMRC), Dhaka, Bangladesh \\ ${ }^{2}$ Department of Physics, Jahangirnagar University, Savar, Dhaka, Bangladesh \\ ${ }^{3}$ Department of Physics, Uttara University, Dhaka, Bangladesh \\ *Corresponding e-mail: nazmul_smrc@yahoo.com
}

\begin{abstract}
The sensitivity test of parameterization schemes for prediction of summer monsoon high impact rainfall events (HIRE) over Bangladesh has been performed using the Fifth-Generation PSU/NCAR Mesoscale Model (MM5) conducting six historical HIRE cases. The MM5 model was run on triple-nested domains at 45, 15, $5 \mathrm{~km}$ horizontal resolutions using Anthes-Kuo (AK), Grell (Gr), Kain-Fritsch (KF), Betts-Miller (BM) and Kain-Fritsch2 (KF2) cumulus parameterization schemes (CPS) with Medium Range Forecast (MRF) and Blackadar planetary boundary layer (PBL).The model predicted rainfall was compared both spatially and quantitatively with Tropical Rainfall Measuring Mission (TRMM) rainfall. While parameterization options of MM5 model have been investigated spatially for Bangladesh, Anthes-Kuo CPS with both MRF and Blackadar $P B L(A K M \& A K B)$ options of MM5 have found suitable. Quantitatively, Anthes-Kuo CPS with MRF PBL (AKM) option has calculated the better average rainfall over Bangladesh. By this way, AKM has found suitable in both spatial and quantitaive comparisons. Thus, Anthes-Kuo CPS with MRF PBL (AKM) has considered as the best MM5 option for prediction of summer monsoon HIRE cases over Bangladesh.
\end{abstract}

Keywords: HIRE, CPS, PBL, MM5 Model, TRMM, Prediction

\section{INTRODUCTION}

Bangladesh $\left(20^{\circ} 34^{\prime}-26^{\circ} 38^{\prime} \mathrm{N}\right.$ and $88^{\circ} 01^{\prime}-92^{\circ} 41^{\prime}$ E) is a disaster prone country. Most of the natural disasters of the country have meteorological origin. The high impact rainfall event (HIRE) causing flash flood is one of those disasters. The extreme rainfall events associated with flash floods which cause severe impacts on the normal rhythm of life through damages of lives and properties are designated as the HIREs $^{1}$. The main socio-economic sectors affected by such rainfall events are - agriculture, infrastructures, human health and social services etc. It is therefore, obvious, that an accurate and reliable prediction of the HIREs of summer monsoon poses to be an important and challenging task.

The role of cumulus parameterization schemes (CPS) is to take the sub-grid scale processes of the cumulus convection, and the planetary boundary layer schemes consider the sub-grid scale processes of the planetary boundary layer (PBL). The development mechanism of rain producing systems, intensity and distribution of rainfall etc are very important to know for weather predictions, water management, flood forecasting, agriculture and many other purposes. But there are very limited facilities are available in Bangladesh to find out the required rainfall data to plan ahead with this issue. Considering this, the sensitivity test of parameterization schemes of CPS in combination with PBL to predict the summer monsoon HIREs over
Bangladesh has been performed using the Fifth-Generation PSU/NCAR Mesoscale Model $(\mathrm{MM} 5)^{2}$. There are several CPS options like Anthes-Kuo (AK), Grell (Gr), Arakawa-Schubert (AS), Fritsch-Chappell (FC), Kain-Fritsch (KF), Bettts-Miller (BM), Kain-Fritsch2 (KF2) are available in MM5 model ${ }^{2}$ and all are not performed equally for same location and season. There are also variations in horizontal resolutions, initial conditions and domain sizes. Thus, the sensitivity test of parameterization schemes for prediction of HIREs over Bangladesh is very much essential. However, in this study, 05 CPS options like AK, Gr, KF, BM, KF2 with Medium Range Forecast (MRF) and Blackadar PBL are tested in triple nested domain. This experiment will lead to select the suitable combination of CPS and PBL for rainfall prediction over Bangladesh.

The summer monsoon seasons of 2004 and 2007 were the two outstanding excess rainfall and flood years in the decade ${ }^{3,4}$. The six HIREs have been selected from these two outstanding excess rainfall and flood years (i.e., 2004 and 2007) for the present Numerical Weather Prediction (NWP) study, which are presented in Fig. 1 and Table 1.

A good number of research works on various aspects of rainfall have been published in the national and international scientific journals and very few of those research works are done using NWP product. For instance, Akter and Islam (2007) 
studied the use of MM5 model for weather forecasting over Bangladesh region ${ }^{7}$ and Akter et. al., (2007) studied the selection of parameterization in MM5 for the estimation of rainfall in Bangladesh $^{8}$. However, all these studies are focused on the pre-monsoon (MAM) rainfall, but the present study is focused on the summer monsoon (JJAS) high impact rainfall. However, A very few works have been done regarding the rainfall activities during summer monsoon season including heavy rainfall / high impact rainfall events using NWP models by Ahasan et. al., $\left(2010^{4}, 2011^{1}, 2013^{9}\right)$, Prasad $\left(2005^{10}\right)$, Das $\left(2009^{11}\right)$ and Islam $\left(2008^{12}\right)$.

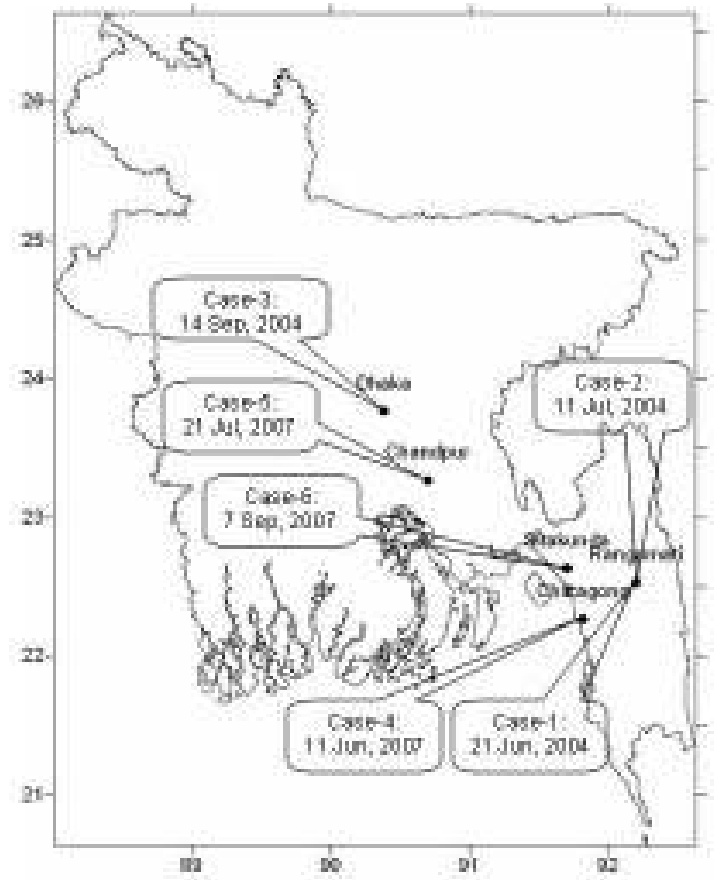

Figure1. Map showing the main representative location of the selected six HIRE cases of Bangladesh for the NWP study.

Table 1. Selected HIRE cases for NWP study

\begin{tabular}{lll}
\hline $\begin{array}{l}\text { Selected cases for } \\
\text { NWP study }\end{array}$ & $\begin{array}{l}\text { Representative } \\
\text { location of the high } \\
\text { impact rainfall }\end{array}$ & $\begin{array}{l}\text { Daily } \\
\text { Observed } \\
\text { Rainfall }\end{array}$ \\
\hline Case-1: 21 Jun, 2004 & $\begin{array}{l}\text { Rangamati and } \\
\text { neighbourhoods } \\
\text { Rangamati and } \\
\text { neighbourhoods } \\
\text { Dhaka, Sandwip } \\
\text { and neighbourhoods } \\
\text { Chittagong and }\end{array}$ & $304 \mathrm{~mm}$ \\
Case-2: 11 Jul, 2004 14 Sep, 2004 & $425 \mathrm{~mm}$ \\
Case-4: 11 Jun, 2007 & $\begin{array}{l}\text { neighbourhoods } \\
\text { Chandpur, Comilla } \\
\text { and neighbourhoods } \\
\text { Sitakunda, Feni } \\
\text { and neighbourhoods }\end{array}$ & $263 \mathrm{~mm}$ \\
Case-6: 7 Sep, 2007 & $195 \mathrm{~mm}$ \\
\hline (Stations in bold face are the main representative location of \\
HIRE)
\end{tabular}

The present study is the new of its kind in the context of sensitivity test of suitable parameterization schemes of MM5 model for prediction of summer monsoon HIREs over Bangladesh, and it is firmly believed that it will improve the general understanding for prediction of the HIREs over Bangladesh using NWP model. Specially, the results will be useful in objective forecasting of the summer monsoon HIREs over Bangladesh using NWP model.

\section{OVERVIEW OF CPS AND PBL OF MM5 MODEL}

An overview of the cumulus parameterizations schemes (CPS) and planetary boundary layer (PBL) schemes of MM5 model used in this study is given below:

\section{Cumulus Parameterization Schemes (CPS)}

Cumulus parameterizations allows different options of cumulus formation considering updraft, downdraft, entrainment, detrainment, compensating, and subsidence which also control heating profile, rainfall efficiency depending on the scale and grid size (Fig. 2). Options of cumulus parameterization schemes are described below:

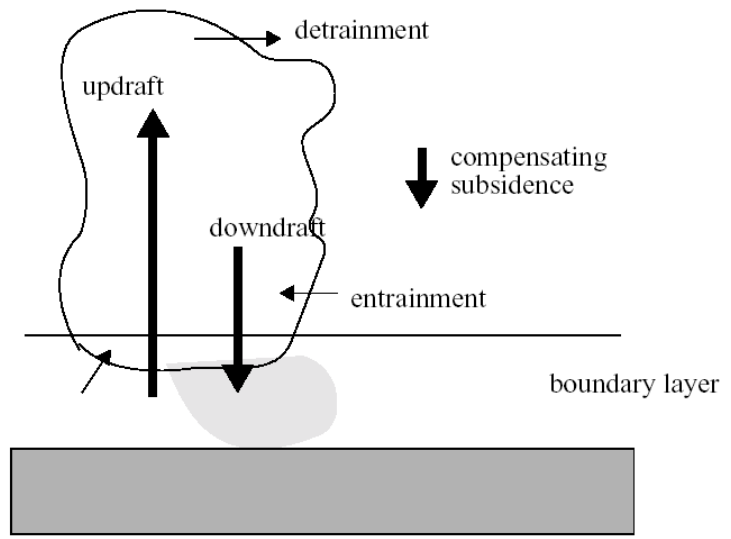

Figure 2. Illustration of cumulus processes.

\section{i) Anthes-Kuo}

The Anthes-Kuo parameterization scheme is based on moisture convergence. It tends to produce much convective rainfall, less resolved-scale precipitation and specified heating profile where moistening is dependent upon relative humidity ${ }^{13}$.

ii) Grell

Based on rate of destabilization or quasi-equilibrium, simple single-cloud scheme with updraft and downdraft fluxes and compensating motion determining heating/moistening profile. Useful for smaller grid sizes 10-30 km, tends to allow a balance between resolved scale rainfall and convective rainfall. Shear effects on precipitation efficiency are considered ${ }^{2}$.

iii) Kain-Fritsch

The Kain-Fritsch scheme is based on a sophisticated cloud-mixing scheme to determine entrainment/detrainment, and removing all available 
buoyant energy in the relaxation time ${ }^{14}$. This scheme predicts both updraft and downdraft properties and also detrains cloud and precipitation. Shear effects on precipitation efficiency are also considered.

\section{iv) Betts-Miller}

Based on relaxation adjustment to a reference post-convective thermodynamic profile over a given period. This scheme is suitable for grid sizes $>30$ $\mathrm{km}$, but there is no explicit downdraft, so it may not be suitable for severe convection ${ }^{15,16,17,18}$.

v) Kain-Fritsch 2

A new version of Kain-Fritsch that includes shallow convection. This is similar to one that is being run in test mode in the Eta model ${ }^{19}$.

\section{Planetary Boundary Layer (PBL) Schemes}

Planetary boundary layer (PBL) schemes are dealing with the process of atmospheric vertical mixing (exchange of energy and vapour), turbulence (Fig. 3). Different PBL options are described below.

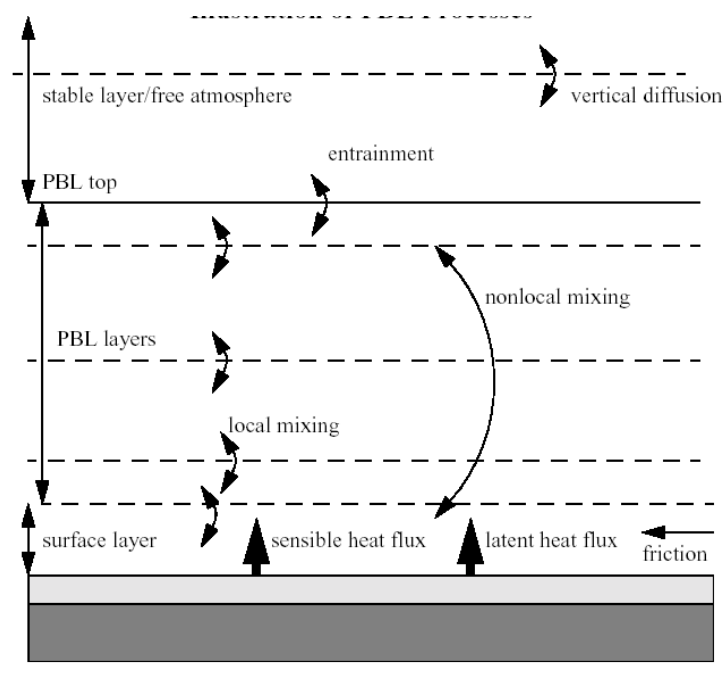

Figure 3. Illustration of planetary boundary layer Processes.

\section{i) High-resolution Blackadar PBL}

Suitable for high resolution PBL, e.g. 5 layers in the lowest $\mathrm{km}$, surface layer $<100 \mathrm{~m}$ thick. Four stability regimes, including free convective mixed layer. Uses split time steps for stability.

\section{ii) $M R F P B L$}

Medium Range Forecast (MRF) or Hong-Pan PBL, suitable for high-resolution in PBL (as for Blackadar scheme). Efficient scheme based on Troen-Mahrt representation of counter gradient term and $K$ profile in the well mixed PBL, as implemented in the NCEP MRF model ${ }^{20}$. This scheme either calls the SLAB routine or the LSM and should have ISOIL $=1$ or 2 . Vertical diffusion uses an implicit scheme to allow longer time steps.

\section{DATA USED, MODEL EXPERIMENTAL SETUP AND METHODOLOGY}

The Fifth-Generation PSU/NCAR Mesoscale model (MM5) version $3.7^{2}$ has been adopted for mesoscale weather research and simulation at SAARC Meteorological Research Centre (SMRC), Dhaka, Bangladesh.

\section{Data used}

The National Center for Environmental Prediction (NCEP) high-resolution Global Final (FNL) Analysis data on $1.0^{\circ} \times 1.0^{\circ}$ grids covering the entire globe every 6-h was taken as the initial and lateral boundary condition. 30 second United States Geological Survey (USGS) data GTOPO30 (Interpolated depending on resolution) were used as topography and 25 Categories USGS were taken as a vegetation / land use. The daily Tropical Rainfall Measuring Mission (TRMM) 3B42V6 rainfall data with $0.25^{\circ} \times 0.25^{\circ}$ resolution rainfall data ${ }^{21}$ are used for comparison with model derived rainfall.

\section{Model experimental set-up and methodology}

The MM5 model was run in the triple nested domain with grids of horizontal resolutions $45 \mathrm{~km}$ for domain D1, $15 \mathrm{~km}$ for domain D2 and $5 \mathrm{~km}$ for domain D3. All the domains are rectangular in shape (Fig. 4). The D3 domain contains the whole territory of Bangladesh and some adjacent territories of the neighbouring countries within its rectangular box. The model rainfall produced within this domain is used for the sensitivity analysis. The 24 hours accumulated rainfall for the selected events as obtained from the model simulation was compared with the corresponding observed rainfall as obtained from TRMM ${ }^{21}$. The TRMM data is continuous over space and the horizontal resolution is comparable with that of the model output which demonstrates extra advantage of using TRMM data compared to BMD rain gauge observations in the meteorological stations having large spatial gaps from one station to other.

The CPSs used in this modelling experiment are Anthes-Kuo ${ }^{13}$, Grell ${ }^{2}$, Kain-Fritsch ${ }^{14}$, Betts-Miller ${ }^{17}$ and Kain-Fritsch $2^{19}$ with 2 PBL schemes namely $\mathrm{MRF}^{20}$ and Blackadar. It is required to select one CPS and one PBL scheme to run the model. It is to note that the results of the model runs are sensitive on the selection of the CPS and PBL schemes. On this consideration, the sensitivity tests are conducted with the 10 pairs of the CPS and PBL combinations (five CPS with two PBL). The model was run for each of these pair parameterization schemes to simulate the rainfall corresponding to all the selected cases. The name AKM, GrM, KFM, BMM and KF2M are used for respective CPSs of Anthes-Kuo (AK), Grell (Gr), Kain-Fritsch (KF), Betts-Miller (BM) and Kain-Fritsch2 (KF2) with MRF (M) PBL scheme, and AKB, GrB, KFB, 
BMB and KF2B for same CPS with Blackadar (B) PBL.

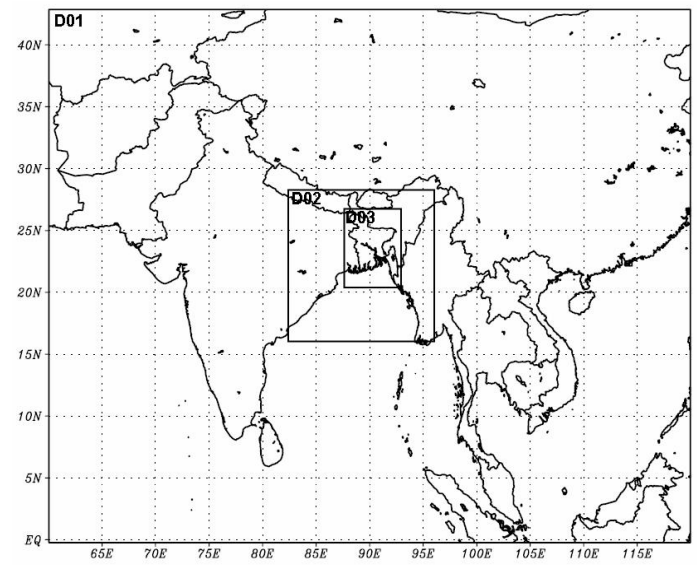

Figure 4. Triple nested domains configuration in MM5 model

The spatial comparison has been made using geographic distribution of the model simulated rainfall and that obtained from TRMM. Again the quantitative evaluation has been made using the graphical representation of the domain average model as well as TRMM rainfall.

\section{RESULTS AND DISCUSSION}

The MM5 model predicted rainfall has been compared in both spatially and quantitatively with TRMM observed rainfall to select the suitable parameterization schemes for prediction of summer monsoon HIREs over Bangladesh.

\section{Spatial comparison with TRMM}

The sensitivity test of ten MM5 options (five CPS with two PBL) has been carried out for the selected six cases to determine the most suitable one out of them. For this purpose, the spatial distribution of daily accumulated rainfall $(\mathrm{mm})$ of five CPS options with MRF PBL and TRMM observed rainfall for the selected six cases are displayed in Fig. 5(a)-10(a). For the same domain and time period the comparison results of five CPS options using Blackadar PBL with TRMM product are shown in Fig. 5(b)-10(b).

\section{Case-1: 21 June, 2004}

It is shown in Fig. 5(a-b) that the rainfall widely varies for different MM5 options. Most of the simulations using different MM5 options have shown heavy rainfall over southeast region of the country, but did not show enough rainfall over the east-central to the northern and the western regions of the country. If these ten figures of MM5 are very closely observed in contrast of TRMM, the options GrM, GrB, KFM, KFB, BMM, BMB, KF2M and KF2B do not considerably match with TRMM as because the results do not exhibit rainfall over the east-central, southeast and west central part of the country. The Anthes-Kuo with both PBL (i.e., AKM, AKB) illustrates almost the similar pattern as compared with TRMM. Hence, Anthes-Kuo with both PBL (i.e., AKM and AKB) may be considered as better MM5 options in this case. However, the spatial distribution corresponding to the AKM option appears to be the best matching with that of TRMM.

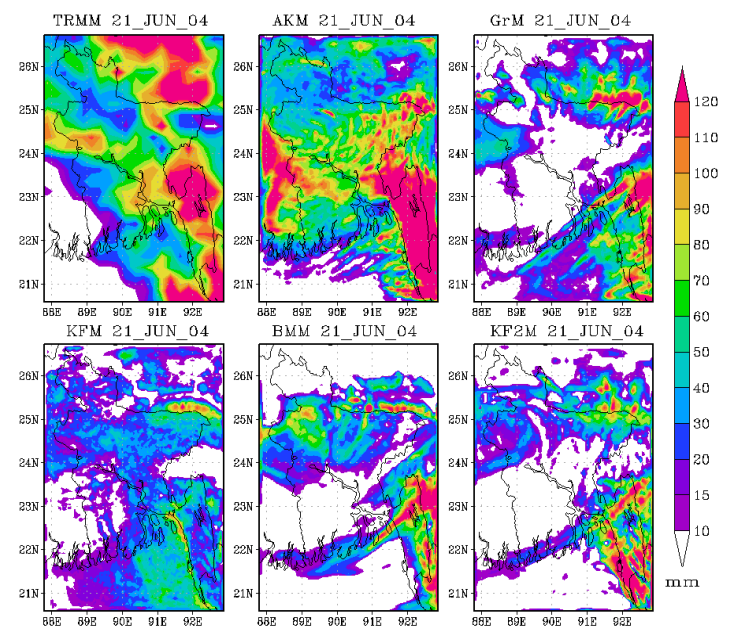

(a)

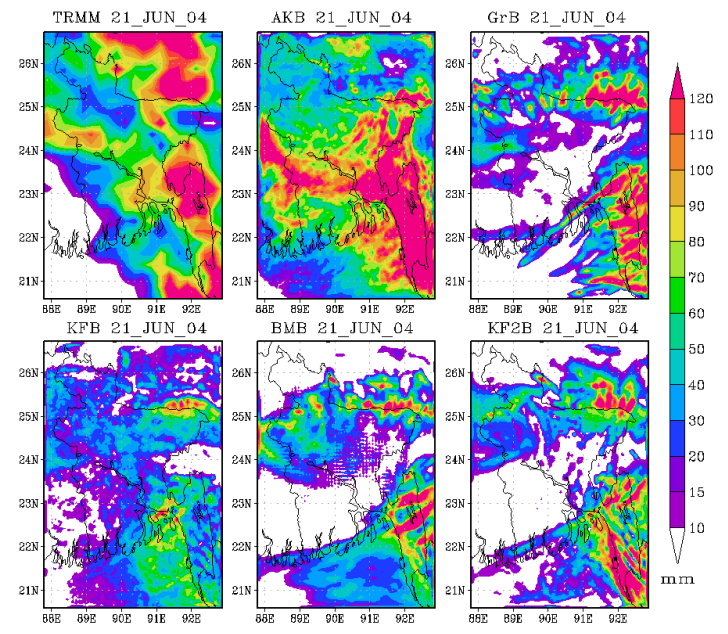

(b)

Figure 5. Spatial distribution of daily accumulated rainfall (mm) for TRMM and five CPS options with (a) MRF PBL, (b) Blackadar PBL on 21 June, 2004 for Bangladesh.

\section{Case-2: 11 July, 2004}

From Fig.6(a-b), it is seen that the MM5 model with all the parameterization options have simulated high rainfall over the southeast, northeast and northwest regions of the country, though the simulated rainfall varied widely for different options. The detail analysis of the spatial distribution of the simulated rainfall against the TRMM observation, it is found that the options KFM, KFB and BMB did not produce realistic 
spatial pattern of rainfall, specially over the southeast region of the domain. In this region considerable amount of rainfall was observed, however, the model simulation did not produce any such rain. On the other hand, the distribution of simulated rainfall obtained using the options GrM, BMM, KF2M and KF2B did not match with TRMM distribution except over the southeast region of the country.
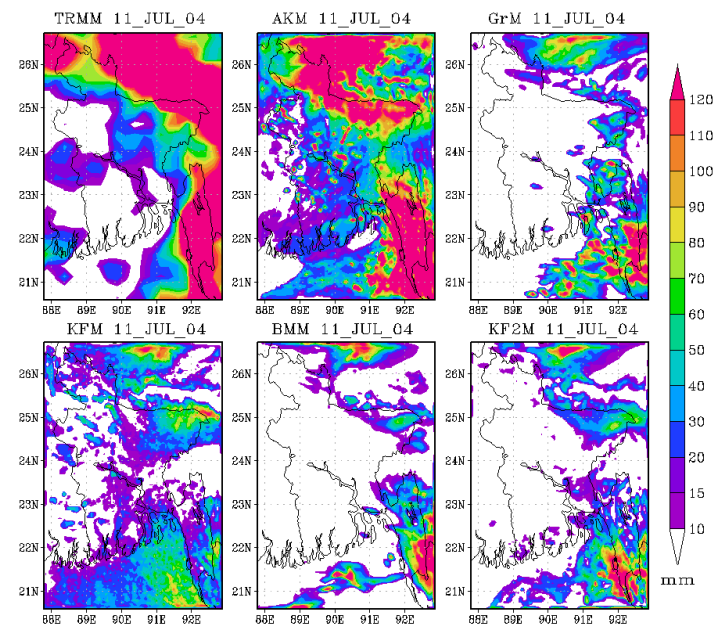

(a)
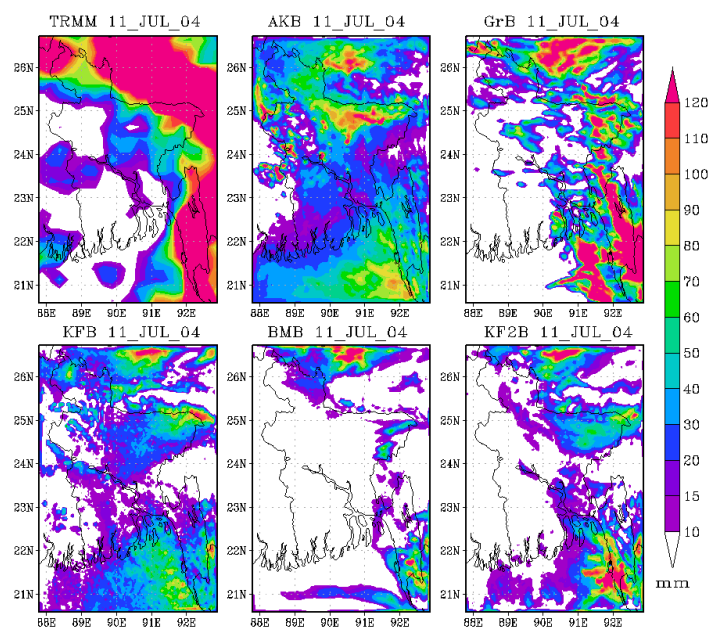

(b)

Figure 6. Spatial distribution of daily accumulated rainfall (mm) for TRMM and five CPS options with (a) MRF PBL, (b) Blackadar PBL on 11 July, 2004 for Bangladesh.

The rainfall over the northeast and northwest regions of the country was not captured by these options. Out of the rest 3 options AKM, AKB and $\mathrm{GrB}$, the latter two (AKB and $\mathrm{GrB}$ ) have simulated considerably low rainfall throughout the country as compared with the TRMM. On the other hand, AKM results illustrated the realistic distribution of the spatial patterns and rainfall intensity. Thus, the Anthes-Kuo with MRF PBL (i.e., AKM) may be considered as the best parameterization options of
MM5 for prediction of rainfall as per the study using this rainfall event.

\section{Case-3: 14 September, 2004}

It is found from Fig.7(a-b) that the rainfall event over the central part of the country has been simulated by all most all the options of MM5, but the intensity and location of the simulated rainfall is different for the individual option. Thorough study of the figures show that rainfall simulation obtained from options GrM, KFM, KF2M, GrB, KFB and BMB do not match with TRMM observation. The spatial structure of the rainfall corresponding to $\mathrm{AKM}$ and $\mathrm{AKB}$ options are found to match fairly well over areas of central Bangladesh showing high intensity rainfall as compared with TRMM. The BMM and KF2B options also
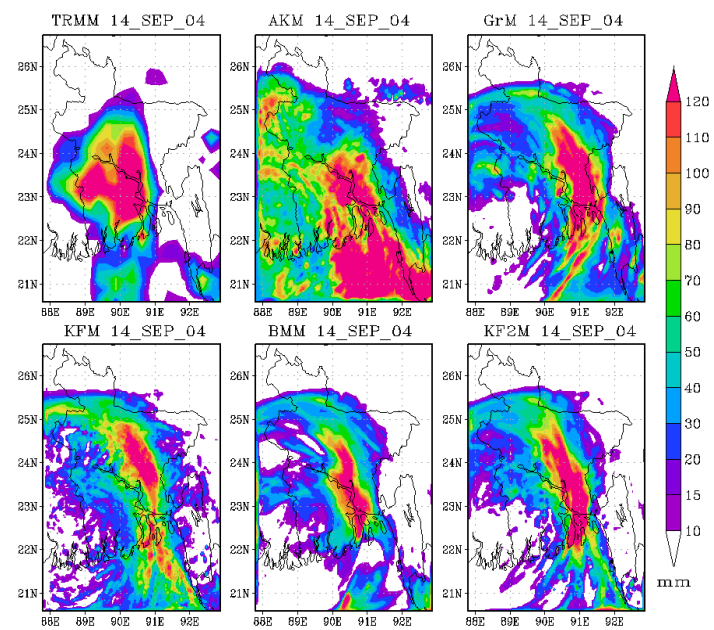

(a)
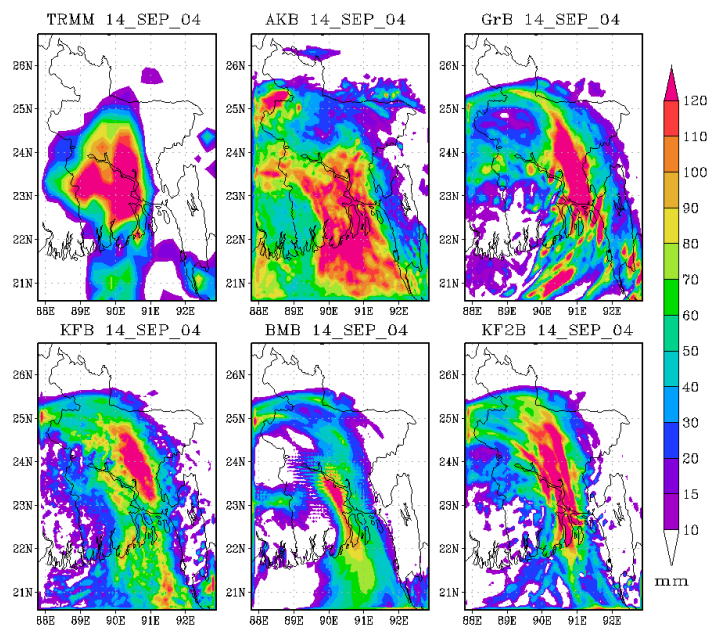

(b)

Figure 7. Spatial distribution of daily accumulated rainfall (mm) for TRMM and five CPS options with (a) MRF PBL (b) Blackadar PBL on 14 September, 2004 for Bangladesh.

captured the rainfall structure as observed with TRMM though the rainfall amount over western part of the country exhibits very low values. However, out of the latter four MM5 options (i.e., AKM, AKB, BMM, 
$\mathrm{KF} 2 \mathrm{~B}$ ), the $\mathrm{AKM}$ and $\mathrm{AKB}$ are found to be closer to the TRMM in the spatial distribution. Thus, the Anthes-Kuo with MRF and Blackadar PBL (i.e., AKM and $\mathrm{AKB}$ ) may be considered as suitable MM5 parameterization options for rainfall simulation considering the case of 14 September, 2004.

\section{Case-4: 11 June, 2007}

It is seen from the Fig.8(a-b) that the rainfall varies widely for the individual parameterization options of MM5. Rainfall over the south and southeast regions of the country captured well by the almost all options, but the intensity and location of high impact rainfall are found to vary quite a lot. If these ten figures of MM5 options are very minutely observed in contrast to TRMM, it is seen that the options KFM, KFB, BMM, BMB, KF2M and KF2B do not considerably matched with TRMM. This is because of the fact that the simulated rainfall over southeast region of the country is much lower for these options compared to the observations.
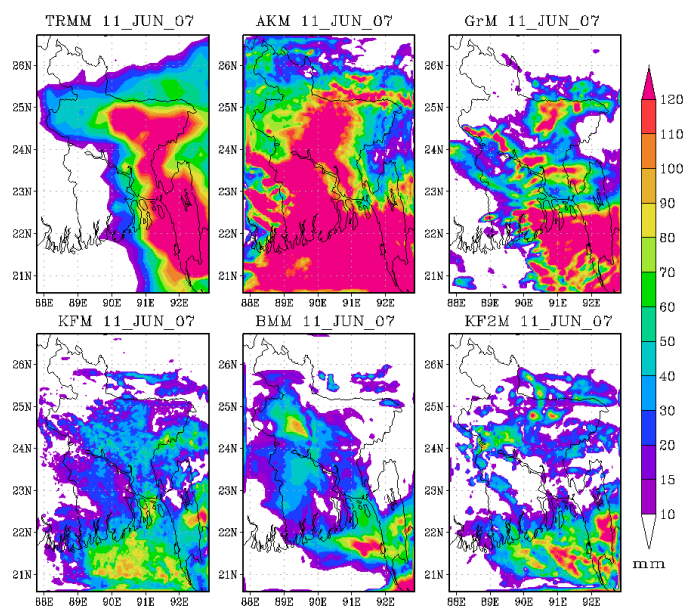

(a)
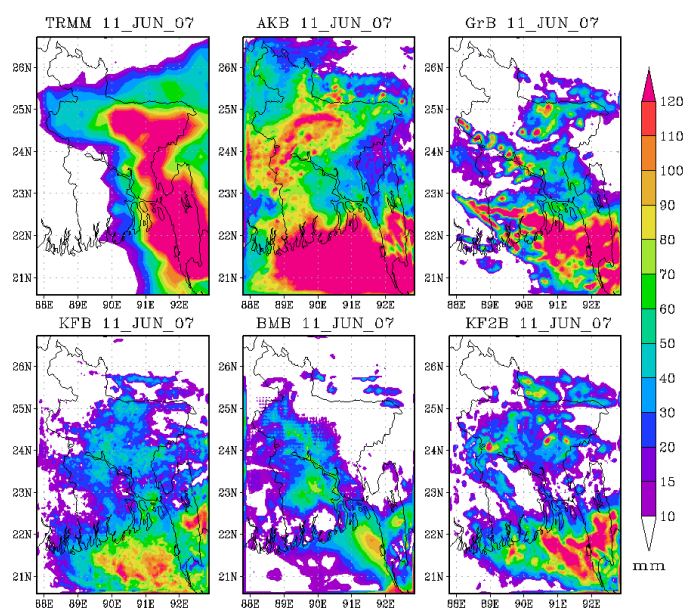

(b)

Figure 8. Spatial distribution of daily accumulated rainfall (mm) for TRMM and five CPS options with (a) MRF PBL, (b) Blackadar PBL on 11 June, 2007 for Bangladesh.
On the other hand, AK and Gr with both MRF and Blackadar PBL (AKM, AKB, GrM and GrB) options illustrate better rainfall structure as compared with TRMM. Out of these options (AKM, $\mathrm{AKB}, \mathrm{GrM}$ and $\mathrm{GrB}$ ) the combinations AKM, GrM and $\mathrm{GrB}$ are found to be close to the TRMM rainfall. AKB simulated relatively high rainfall over the southern part of the country, but simulated rainfall is much lower than the observed over Chittagong and its neighbourhoods. Among these three options (AKM, GrM and GrB), GrM and GrB simulations are too low over the north and northeast regions of the country. Thus, the Anthes-Kuo with MRF PBL (i.e., AKM) may be considered as the best MM5 options for the case.

\section{Case-5: 21 July, 2007}

Figure 9(a-b) shows that all the selected parameterization options produced rainfall over the central and south-central part of the country and adjacent areas of the Bay of Bengal. However, the
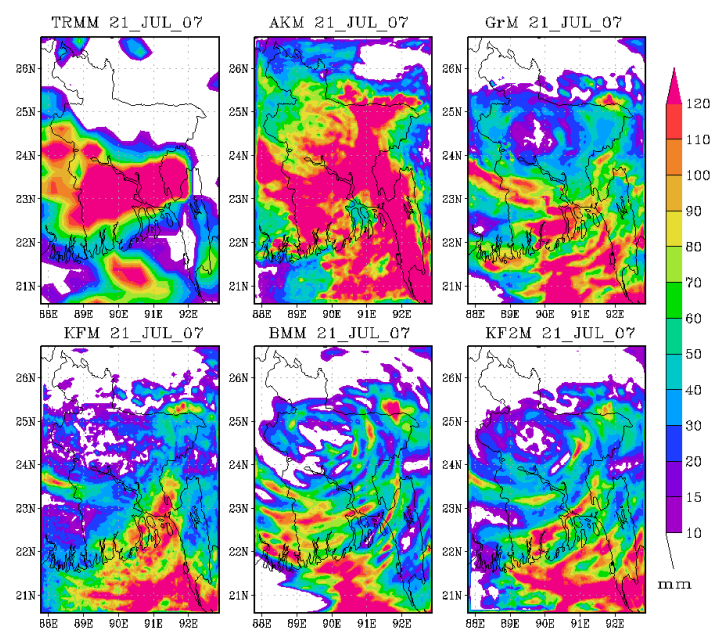

(a)
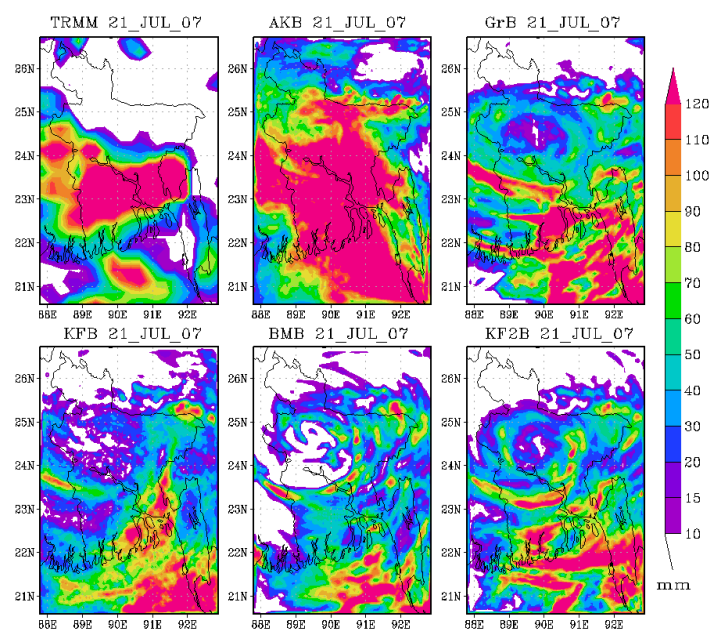

(b)

Figure 9. Spatial distribution of daily accumulated rainfall (mm) for TRMM and five CPS options with (a) MRF PBL, (b) Blackadar PBL on 21 July, 2007 for Bangladesh. 
intensity was different for different parameterization options. When these ten figures of parameterization options are minutely investigated in contrast to TRMM, the rainfall produced using the options Gr, $\mathrm{KF}, \mathrm{BM}$ and KF2 with both MRF and Blackadar $\mathrm{PBL}$ it was found that the model simulated rainfall did not match with the rainfall obtained from TRMM. The simulated rainfall over the central and east-central part of the country is much lower for these options compared to TRMM. Further comparison of AKM and AKB against TRMM, it is seen that $\mathrm{AKB}$ exhibits much larger area with high rainfall compared to both AKM and TRMM. Thus, it comes out that AKM option produces realistic distribution with slightly higher coverage of heavy rainfall.

\section{Case-6: 7 September, 2007}

It is found from Fig.10(a-b) that almost all MM5 options produced rainfall over northwest, south and

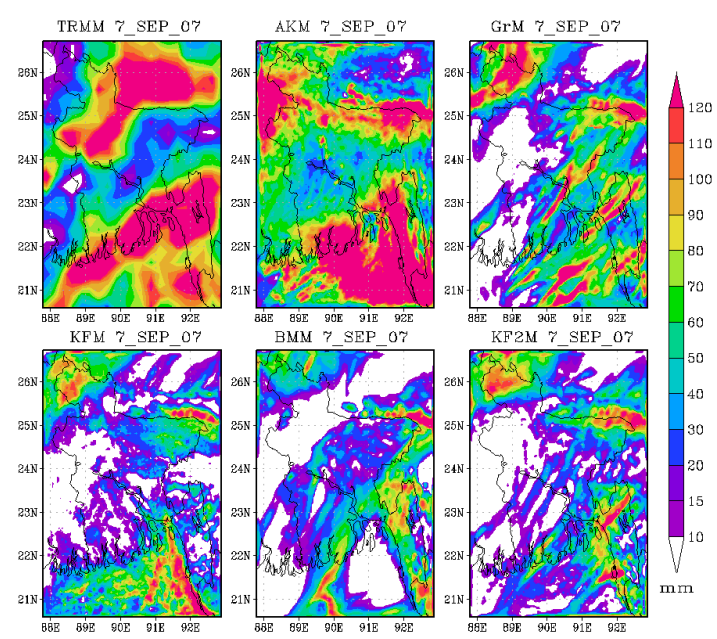

(a)

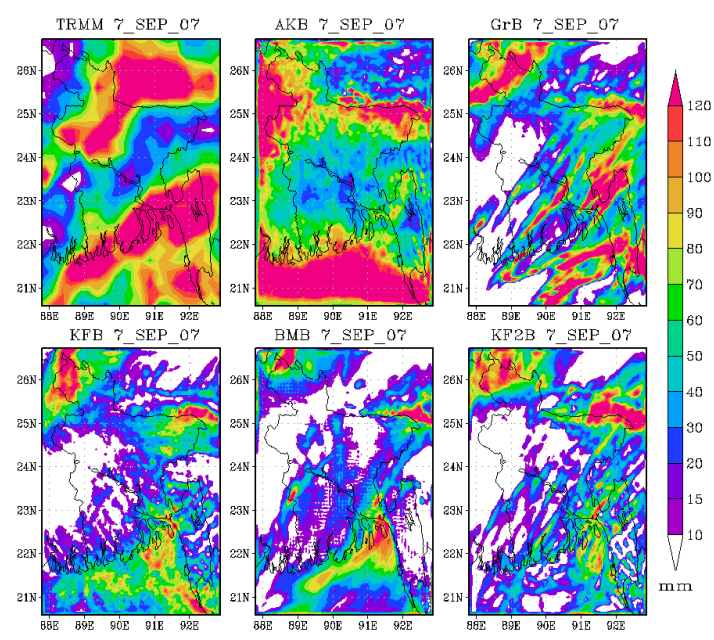

(b)

Figure10. Spatial distribution of daily accumulated rainfall (mm) for TRMM and five CPS options with (a) MRF PBL, (b) Blackadar PBL on 7 September, 2007 for Bangladesh. southeast regions of the country, but the physical intensity and location of the simulated rainfall varied widely for the individual options. These ten figures (showing the MM5 simulated rainfall) are very closely observed in contrast of TRMM data and found that the KFM, KFB, BMM, BMB, KF2M, KF2B do not match with TRMM. This is because that the rainfall over the southeast part of the country has poorly been simulated by these MM5 options. However, the AKM, AKB, GrM and GrB simulated rainfall shows some similarity with that of observed ones by TRMM. Among these four options, the $\mathrm{AKB}, \mathrm{GrM}$ and $\mathrm{GrB}$ produced very low rainfall as compared with TRMM. On the other hand, the spatial distribution of rainfall using AKM is quite good as compared with TRMM. Thus, AKM may be considered as the best MM5 option for this high impact rainfall case.

\section{Quantitative comparison with TRMM}

The quantitative comparison between model simulated area average rainfall of ten parameterization options (five CPS with two PBL) over Bangladesh with TRMM rainfall has been carried out. The graphical representation of these quantitative values are illustrated as bar diagram in Fig.11-16.

\section{Case-1: 21 June, 2004}

From Fig.11, it is evident that the AKM gives a little higher intensity $(72.03 \mathrm{~mm})$ of rainfall compared to that of TRMM $(64.04 \mathrm{~mm})$, while the AKB option produces higher rainfall $(77.61 \mathrm{~mm})$ than AKM. The AKM overestimates the TRMM observed rainfall of the order of $12 \%$. Others give much lower value compared to that of TRMM. It was mentioned earlier that the TRMM always underestimates the monsoon rainfall over Bangladesh $^{22}$. Based on this it is considered that the actual rainfall would be slightly higher than that observed by TRMM. Hence, the Anthes-Kuo with MRF (i.e., AKM ) option which produces rainfall higher than but close to TRMM rainfall may be considered as the best MM5 option in this case based on the quantitative analysis.

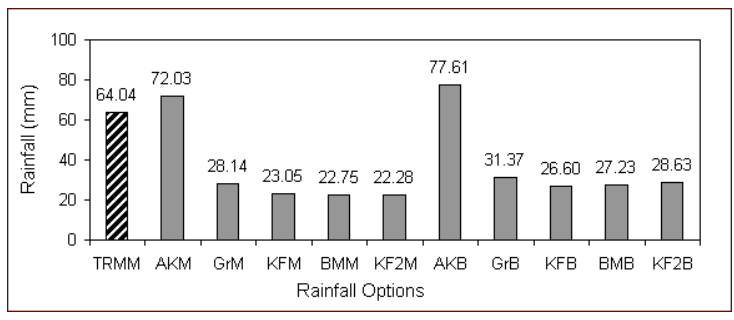

Figure 11. Quantitative comparison of model simulated daily area average rainfall $(\mathrm{mm})$ of 10 parameterization options with that of TRMM on 21 June, 2004 for Bangladesh. 
Case-2: 11 July, 2004

It is found from the Fig.12 that the AKM and AKB give higher intensity (36.28 and $35.44 \mathrm{~mm}$ respectively) with respect of TRMM $(29.28 \mathrm{~mm})$. Others give lower value than TRMM. Considering that TRMM always underestimates the monsoon rainfall over Bangladesh ${ }^{22}$, the actual rainfall will be slightly higher than that observed by TRMM. However, it is seen that AKB overestimated the rainfall by $21 \%$ over the TRMM and did not qualify in the test performed through spatial comparison. GrB $(25.75 \mathrm{~mm})$ underestimated the rainfall by $12 \%$ compared to the TRMM and has shown severe drawback in the spatial distribution. On the other hand, AKM overestimated the rainfall with respect to TRMM by $24 \%$ which is acceptable as TRMM always underestimates monsoon rainfall. It also exhibited fairly good matching with TRMM in spatial distribution as well. Thus, the Anthes-Kuo with MRF PBL (i.e., AKM) may be considered as suitable parameterization options for rainfall prediction in this case.

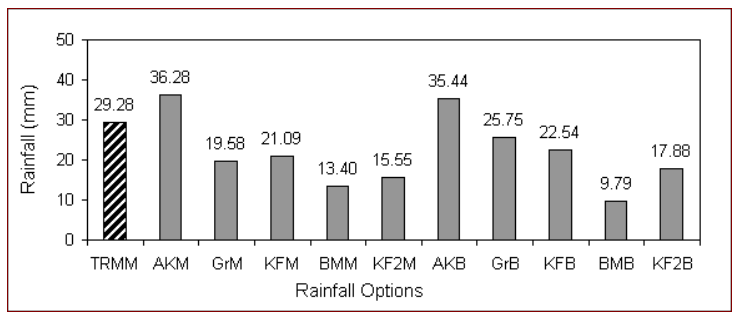

Figure12. Quantitative comparison of model simulated daily area average rainfall $(\mathrm{mm})$ of 10 parameterization options with that of TRMM on 11 July, 2004 for Bangladesh.

\section{Case-3: 14 September, 2004}

From Fig.13, it is found that all the parameterization schemes of MM5 except AKM and AKB underestimated the rainfall in comparison to that obtained from TRMM. It may be noted that for the options GrM and GrB the domain average rainfall stands close to the TRMM rainfall, but they have a severe drawback in spatial domain distribution. AKM and AKB overestimated the TRMM rainfall in the order of $29 \%$ and $15 \%$ respectively. Considering the fact that TRMM always underestimates the monsoon rainfall over Bangladesh, the actual rainfall will be higher but close to the TRMM observation. Thus, the Anthes-Kuo with MRF and Blackadar PBL (i.e., $\mathrm{AKM}$ and $\mathrm{AKB}$ ) may be considered as the suitable MM5 options for rainfall prediction.

\section{Case-4: 11 June, 2007}

It is evident from the Fig. 14 that the AKM and AKB give a higher intensity $(57.65$ and $56.20 \mathrm{~mm}$ respectively) with respect of TRMM $(52.31 \mathrm{~mm})$. The other options give lower values than TRMM.
$\mathrm{AKM}$ and $\mathrm{AKB}$ are very close to TRMM, but AKB has a severe drawback in spatial distribution. Thus, Anthes-Kuo with MRF PBL (i.e., AKM) exhibits the best performance based on which this combination has been chosen as the best MM5 option for this case.

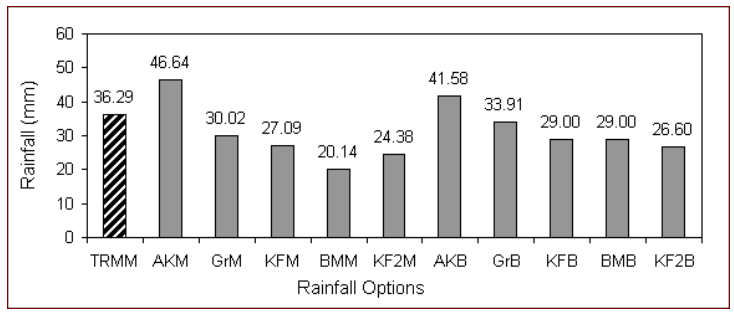

Figure13. Quantitative comparison of model simulated daily area average rainfall $(\mathrm{mm})$ of 10 parameterization options with that of TRMM on 14 September, 2004 for Bangladesh.

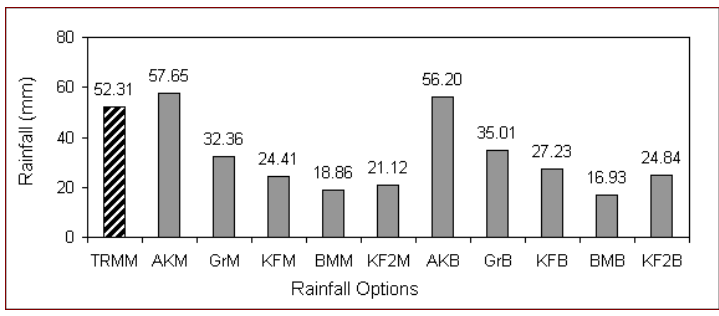

Figure 14. Quantitative comparison of model simulated daily area average rainfall $(\mathrm{mm})$ of 10 parameterization options with that of TRMM on 11 June, 2007 for Bangladesh.

\section{Case-5: 21 July, 2007}

From the Fig. 15, it is evident that the AKM (78.44 $\mathrm{mm})$ and $\mathrm{AKB}(80.40 \mathrm{~mm})$ fairly overestimate rainfall as compared with the rainfall obtained from TRMM (50.04 mm). Other options give lower estimates than the observed ones from TRMM. The rainfall obtained from GrM option is close to that obtained from TRMM, but it has large discrepancy in the spatial comparison. It has been found from the spatial comparison that the AKM provides better spatial pattern.

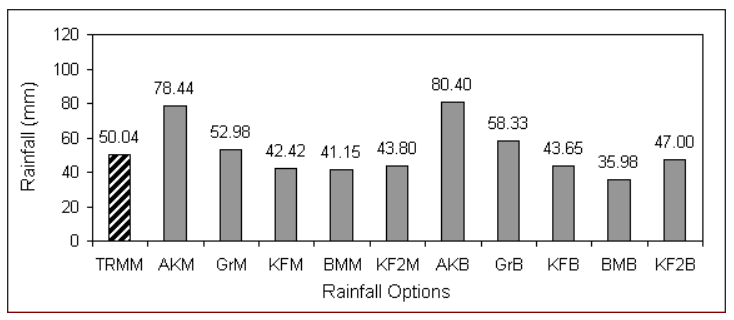

Figure 15. Quantitative comparison of the model simulated daily area average rainfall $(\mathrm{mm})$ of 10 parameterization options with that of TRMM on 21 July, 2007 for Bangladesh. 


\section{Case-6: 7 September, 2007}

It is found from Fig.16 that AKM slightly overestimated (5\%) the TRMM observed rainfall. The AKB simulated rainfall is very close to TRMM, but it has severe drawback in the spatial domain distribution. On this consideration, AKM is taken as the best pair of parameterization option in this case.

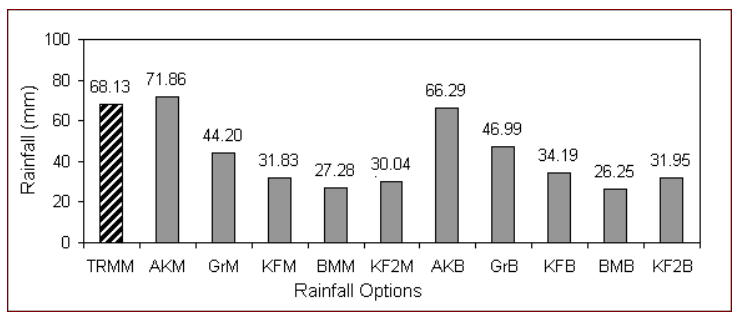

Figure16. Quantitative comparison of model simulated daily area average rainfall $(\mathrm{mm})$ of 10 parameterization options with that of TRMM on 7 September, 2007 for Bangladesh.

\section{Consolidated results obtained from the sensitivity test}

The consolidated results of spatial and quantitative comparison of the simulated rainfall using 10 parameterization options (5 CPS with 2 PBL schemes) with TRMM observed rainfall for all the six HIRE cases of summer monsoon over Bangladesh are synthesized in Table 2.

Table 2. Consolidated results of spatial and quantitative comparison of simulated rainfall using parameterization options (5 CPS with 2 PBL schemes) of MM5 with TRMM rainfall.

\begin{tabular}{lcc}
\hline \multicolumn{1}{c}{ Cases } & Spatial & Quantitative \\
\hline Case-1: 21 Jun, 2004 & AKM & AKM \\
Case-2: 11 Jul, 2004 & AKM & AKM \\
Case-3: 14 Sep, 2004 & AKM, AKB & AKM, AKB \\
Case-4: 11 Jun, 2007 & AKM & AKM, AKB* \\
Case-5: $21 \mathrm{Jul}, 2007$ & AKM, AKB & AKM, GrM* \\
Case-6: 7 Sep, 2007 & AKM & AKM \\
*There is a severe drawback in spatial distribution, but it has \\
good agreement in quantitative comparison.
\end{tabular}

The Anthes-Kuo with MRF PBL (i.e., AKM) has been found suitable MM5 options for all the cases in spatial and quantitative comparison. On the other hand, the Grell with MRF PBL (i.e., GrM) and the Anthes-Kuo with Blackadar PBL (i.e., AKB) are also found good MM5 option in only quantitative evaluation, but there are severe drawbacks in spatial distribution. Finally the Anthes-Kuo with MRF PBL (i.e., AKM) may be considered as the best parameterization option of MM5 for the prediction of summer monsoon rainfall over Bangladesh.

\section{CONCLUSIONS}

On the basis of the present study, the following conclusions can be drawn:

1. The Anthes-Kuo CPS with MRF PBL (AKM) has found the best suitable parameterization scheme among ten combinations of CPS and PBL options of MM5 as compared with TRMM in both spatially and quantitatively.

2. Anthes-Kuo CPS with Blackadar PBL (AKB) has also found good MM5 option in both spatial and quantitative evaluation in case of some events. But, AKB may either underestimates the TRMM observed rainfall or have severe brawback in spatilal comparison. Thus, AKB may be considered as second option.

3. The Grell CPS with MRF PBL (GrM) has predicted better average rainfall in few cases. But, TRMM is always underestimated the GrM predicted rainfall in quantitative comparison and there are severe drawbacks in spatial distribution. Thus, GrM may be considered as third option.

Finally, it may be concluded that the Anthes-Kuo CPS with MRF PBL (AKM) option of MM5 modeling systems has been considered as suitable parameterization scheme for prediction of summer monsoon high impact rainfall events over Bangladesh.

\section{Acknowledgement}

The first author is grateful to Dr. Md. Nazrul Islam, Professor, Department of Meteorology, King Abdul Aziz University, Jeddah, K. S. A. for helpful suggestions and encouragement.

\section{REFERENCES}

1. M. N. Ahasan, M. A. M. Chowdhury and D. A. Quadir, 2011 "Simulation of a heavy rainfall event on 14 September 2004 over Dhaka, Bangladesh using MM5 model”, J. Sci. Res., vol. 3, no.2, pp. 261-270.

2. G. A. Grell, J. Dudhia and D. R. Stauffer, 1994, "A description of the fifth-generation Penn State/NCAR Mesoscale Model (MM5)", NCAR Tech Note, NCAR/TN-398+STR, $117 \mathrm{pp}$.

3. M. N. Ahasan, M. A. M. Chowdhury and D. A. Quadir, 2008, "A few aspects of the flood disaster caused by heavy monsoon rainfall in Bangladesh", Proceedings of SAARC seminar on application of weather and climate forecasts in the socio-economic development and disaster mitigation, 5-7 August, 2007, Dhaka, Bangladesh, pp.79-94.

4. M. N. Ahasan, M. A. M. Chowdhury and D. A. Quadir, 2010, "Variability and trends of summer monsoon rainfall over Bangladesh", J. of Hydrology and Meteorology, Nepal, vol. 7, no. 1, pp. 1-17.

5. SMRC News Letter, SAARC Meteorological Research Centre (SMRC), vol.-11, no.2, 2004. 
6. SMRC News Letter, SAARC Meteorological Research Centre (SMRC), vol.-14, no.1, 2007.

7. Nasreen Akter and M. N. Islam, 2007, "Use of MM5 model for weather forecasting over Bangladesh region, BRAC University Journal, vol. 4, no. 1, pp. 75-79.

8. Nasreen Akter, M. N. Islam, T. Terao and T. Hayashi, 2007, "Selection of parameterization in MM5 for the estimation of rainfall in Bangladesh", Bangladesh Journal of Physics, vol. 3, pp. 75-83.

9. M. N. Ahasan, M. A. M. Chowdhury and D. A. Quadir, 2013, "Simulation of a heavy rainfall event of 11 June 2007 over Chittagong, Bangladesh using MM5 model", MAUSAM, 64(3), pp. 405-416.

10. K. Prasad, 2005, "Monsoon Forecasting with a limited area numerical weather prediction system", SAARC Meteorological Research Centre, Scientific Report No.-11, 82 pp.

11. S. Das, 2009, "Studies of Tornadic Storms over Bangladesh using Radar and WRF Model", SAARC Meteorological Research Centre, SMRC Scientific Report No-28, 45 pp

12. M. N. Islam, 2008, "Studies of summer monsoon rainfall using regional climate model PRECIS", SAARC Meteorological Research Centre (SMRC), Scientific Report No-22, 28 pp.

13. R. A. Anthes, 1977, Cumulus parameterization scheme utilizing a one dimensional cloud model, Monthly Weather Review, 105, pp. 270-286.

14. J. S. Kain, and J. M. Fritsch, 1993, "Convective parameterization for mesoscale models: The Kain-Fritsch scheme, the representation of cumulus convection in numerical models", K. A. Emanuel and D. J. Raymond, Eds., American Meteorological Society, 246 pp.
15. A. K. Betts, 1986, “A new convective adjustment scheme, Part I: Observational and theoretical basis”, Quart. J. Roy. Meteor. Soc., 112, pp. 677-692.

16. A. K. Betts and M. J. Miller,1986, "A new convective adjustment scheme, Part II: Single column tests using GATE wave, BOMEX, ATEX and Arctic air-mass data sets", Quart. J. Roy. Meteor. Soc., 112, pp. 693-709.

17. A. K. Betts and M. J. Miller, 1993, "The Betts-Miller scheme: The representation of cumulus convection in numerical models", K. A. Emanuel and D. J. Raymond, Eds., Amer. Meteor. Soc., 246 pp.

18. Z. I. Janjic, 1994, "The step-mountain eta coordinate model: Further development of the convection, viscous sublayer, and turbulent closure schemes", Mon. Wea. Rev., 122, pp. 927-945.

19. J. S. Kain, 2002, "The Kain-Fritsch Convective Parameterization: An Update", J. of Applied Meteorology, 43, pp. 170-181.

20. S. Y. Hong and H. L. Pan, 1996, "Nonlocal bloudary layer vertical diffusion in a medium-range forecast model", Monthly Weather Review, vol. 124, pp. 2322-2339.

21. TRMM Data Users Handbook, 2001, Earth Observation Centre, National Space Development Agency of Japan.

22. M. N. Islam and T. Uyeda, 2007, "Use of TRMM in determining the climatic characteristics of rainfall over Bangladesh", Remote Sensing of Environment, vol. 108, pp. 264-276. 